\title{
The Color of Natural Teeth Investigated by Visual Perception and Spectrophotometer
}

\author{
Teuta Pustina-Krasniqi ${ }^{1}$, Ariana Bytyçi ${ }^{2}$, Teuta Bicaj ${ }^{1}$, Enis Ahmedi' ${ }^{1}$,inda Dula ${ }^{1}$, \\ Zana Lila ${ }^{1}$, Arlinda Dragusha1, Nexhmije Ajeti ${ }^{3}$ \\ ${ }^{1}$ Department of Prosthetic Dentistry, Dental Branch, Medical Faculty, University of Prishtina, Prishtina, Kosovo \\ ${ }^{2}$ Private Dental Office, Prishtina, Kosovo \\ ${ }^{3}$ Department of Endodontic and Dental Pathology, Dental Branch, Medical Faculty, University of Prishtina, \\ Prishtina, Kosovo \\ Email: teutapustina@hotmail.com
}

Received 26 December 2014; accepted 23 January 2015; published 30 January 2015

Copyright (C) 2015 by authors and Scientific Research Publishing Inc.

This work is licensed under the Creative Commons Attribution International License (CC BY).

http://creativecommons.org/licenses/by/4.0/

\section{(c) (i) Open Access}

\section{Abstract}

The advantage of electronic devices is to eliminate the subjectivity. Based on individual capabilities, visual perception has its disadvantages. The aim of this study was to find out the possible shade difference between the upper and lower teeth, visual perception versus spectrophotometry as well as proving that females are better in visual perception of colour matching. 82 subjects (dental students) of this study determined the color of each other's natural teeth. The color of 1640 teeth (incisors, canines and premolars), was matched by visual perception and by Vita Easyshade spectrophotometer. The matching was focused on the middle third of buccal surfaces of the examined teeth. In this study, it was found that there was a difference of color between the teeth of the upper and lower jaw. The percentage of the accordance between two methods was $28.35 \%$ for all examined teeth. The color determination at central incisors showed the highest value of accordance $40.85 \%$. Based on Vitapan 3D Mastershade, the most frequent color was 2M2.

\section{Keywords}

Teeth Color, Visual Perception, Spectrophotometer, Accordance

\section{Introduction}

Color vision is part of a visual perception and a complex process occurring in the brain. Color realisation is the

How to cite this paper: Pustina-Krasniqi, T., Bytyçi, A., Bicaj, T., Ahmedi, E., Dula, L., Lila, Z., Dragusha, A. and Ajeti, N. (2015) The Color of Natural Teeth Investigated by Visual Perception and Spectrophotometer. Open Journal of Stomatology, 5, 2635. http://dx.doi.org/10.4236/ojst.2015.52005 
result of three processes: stimulation, sensation and perception. A beam of light is absorbed, reflected, transmitted by the tooth through a complex set of interacting optical phenomena. The appearance of a tooth is affected by the interaction of its optical properties and spatial arrangement of the light, observer and tooth [1].

The tubules are the predominant cause of light scattering in dentin and hydroxyl apatite crystals in the enamel [2].

The teeth color is determined by the dentin, with translucent enamel, which is playing a lesser role through scattering at wavelengths in the blue range [3]. It was reported that: shade selection is a crucial clinical step during prosthetic treatment [4]. During the visual teeth color determination it is suggested that the first impression is frequently the best match, and shade matching trials should be limited to 5 seconds at a time to prevent eye fatigue, because the vision pigment is used up quickly in the mechanism of color perception. Many times in the dental literature has been given the recommendation to relax the eyes by observing a blue card between two shade matching trials (because blue and yellow are complementary colors) [5]. Generally, based on the literature percentage of color deficiency at women is lower. It is an opinion that women can match tooth color better [3]-[6].

Based on some other findings men and women shade matching abilities are same [7]. Based on Paravina, approximately $8 \%$ of men and $0.5 \%$ of woman were found to be color deficient [8]. Dental studies reported color deficiency from $7.8 \%$ to $14 \%$ [9]-[13].

Many authors advise that dental students, dentists and technician need to undergo in color vision testing. [14] [15]. Based on the suggestions, during the color determination a three step method should be used, as follows: 1) Using the rearranged shade guide, pick two to four tabs of the closest shade to the tooth being matched and separate them from the other tabs; 2) Choose the closest shad tab or combination of appropriate shade tabs; 3 ) Visualize surface roughness, gloss, translucency/opacity and other appearance parameters as well as local color characteristics [1]. Color measurement instruments have appeared recently, trying to correct the problems of conventional technique [16]. The Vita company also introduced the Vita EASYSHADE ${ }^{\circledR}$ spectrophotometer for tooth shade matching. Shade evaluation with the spectrophotometer used in that study showed a high degree of correlation with visual shade determination of the color of natural teeth [17].

The oldest color system was created by Albert H. Munsell in 1905. Consists from three attributes-hue (H), value or lightness (V) and chroma (C), denoted as H/V/C.

Value/Lightness is the quantity of light reflected by an object compared to a pure white diffuser (reflecting $100 \%$ ), and a black absorber (absorbing all incident light with no reflection). If a material reflects most of the light falling on its surface, it appears bright, i.e. it has a high value. Conversely, a dark object absorbs most of the incident light and appears dull, i.e. it has a low value. Between the two extremes (white and black) a gradation of value exists and is termed the grey-scale [18].

Chrome is an open-ended scale operating from 0 (achromatic colors) to maximum depending on the hues. It describes a visual perception as the degree of departure of the color from an achromatic color of the same lightness. Chroma (saturation) may be defined as the strength or dominance of the hue. On the outer edge of the hue wheel are the pure hues. Towards the center of the color wheel, no hue dominates and becomes less and less saturated [1].

Hue is described with the words we normally think of as describing color: red, purple, blue, etc. It is also a term which describes a dimension of color we readily experience when we look at color.

In the early 1990s, the Vita company introduced the 3D Mastershade guide, with the aim of accurately assessing shade according to the three components of colour: hue, value and chroma. 3D Mastershade guide was chosen for visual teeth color matching, because it has tabs arranged systematically and logically, rather than randomly as in the previously used guides. The 3D Master guide represents the multi-layers of natural teeth. Vita value, Vita chroma and Vita hue, similarly to the Munsell hue, value and chroma color co-ordinates, which represent the three dimensions of color. The tabs are grouped into five categories, sequentially numbered, with an increasing value (1, 2, 3, 4 and 5). All tabs within a value group have the same brightness. In a given value group, the chroma increases from top to bottom. All groups, with the exception of 1 and 5 , are designated three letters, L, M and R, corresponding to varying hue. For example L (light) is indicative of a yellow, M (medium) of a yellow-red or orange, and R (red) of a red hue. Documentation for the 3D guide is analogous to the Munsell Renotation System, comprising a number/letter/number configuration. The first number indicates the value group (1 to 5), the letter is the hue (L, M or R) and the second number the chroma (1, 1.5, 2, 2.5 or 3). For example 2M2 corresponds to the second value group, the $\mathrm{M}$ hue sub-group and a 2-chroma level. For an interme- 
diate tooth shade, a combination of two tabs is used for the final color prescription [1].

\section{Aim of the Study}

Based on, that digital devices are more accurate in teeth color determination, the aim of this study, was: to find out if there is a difference between visual perception and spectrophotometer reading, to find out the possible 3D Mastershade differences between the teeth of the upper and lower jaw, to prove that females are better in visual perception of colour matching.

\section{Materials and Methods}

\subsection{Participants}

For tooth color matching a total of 82 subjects participated. They all were dental students of University Dental Clinical Center of Kosovo (40 female and 42 male students), whose age ranged between 20 and 25 (average age 21.9). A total of 20 teeth were examined for color matching (8 incisors, 4 canines and 8 premolars). The total number of the examined teeth was 1640 .

\subsection{Observers}

Observers were the same dental students, who matched the teeth color of 82 subjects by visual perception, divided into two groups: females and males. The shade of 720 teeth was determined by female observers and the shade of 920 teeth by male observers.

Prior the visual color matching the female subjects were asked to remove lipstick if any. The shade of the teeth was matched early in the morning. In order to avoid eye fatigue, the observers were instructed to watch the tooth for no longer than 5 seconds.

\subsection{Visual Tooth Shade Matching}

The 3D Mastershade guide (Vita Zahnfabrik H. Rauter GmbH \& Co. KG, Bad Sackingen, Germany) was used for visual tooth color matching, because it has tabs arranged systematically and logically, rather than previously used shade guides. The 3D Master attempts a three-dimensional analysis of tooth color. The color space occupied by the guide is similar to natural dentition, between the $\mathrm{a}^{*}$ (red) and $\mathrm{b}^{*}$ (yellow) color co-ordinates of the CIE L*a*b* system. The tooth color matching was determined upon comparison of the digital tooth shade matching.

The spectrophotometer Vita Easyshade ${ }^{\circledR}$ (Vita Zahnfabrik H. Rauter GmbH \& Co. KG, Bad Sackingen, Germany) was used for digital tooth shade matching. It is a handheld spectrophotometer for tooth shade matching. The instrument consists of a handpiece and a base unit, which are connected by a monocoil fiberoptic cable assembly ${ }^{2}$. In fact, the Vita Easyshade measures 16 Vita Classical shades, 29 Vita 3D-Master ${ }^{\circledR}$ shades and intermediate shades. The matching was concentrated on the middle third of buccal surfaces of the examined teeth. The deviation up to 0.5 units is considered as a tolerance limit (for example: 0.5M1.5 - 1M1.5; or 1.5L2 - 2L2). This is done because intermediate shades of Vita Easyshade do not exist in Vitapan 3D Mastershade guides. This is a characteristic of the spectrophotometer Vita Easyshade in which we can find and intermedier colors, such as: $0.5 \mathrm{M} 1.5,2.5 \mathrm{~L} 2.5$, etc. The most frequent supposed combination (MFSC) consists from the most numerous levels of three shade qualities Lightness/Hue/Chrome (L/H/C), whereas the most frequent shade (MFSh) represents the frequent repeated shade.

\section{Results}

The tooth color was matched on 82 subjects ( 40 females and 42 males), respectively (48.8\% females and 51.2\% males). There was no significant age difference. The average age of the subjects was 21.9. The age and gender of the participants is presented in Table 1.

The total number of the analyzed teeth was 1640 . The results of the shade matching, between the visual perception and the spectrophotometer are presented in the Table 2. Shade evaluation with the spectrophotometer, showed a degree of accordance with visual shade determination, in 465 (total 1640) teeth or in $28.35 \%$ of the teeth. In the lower jaw the determination of the color showed a high degree of accordance between two methods 
Table 1. Age and gender of participants.

\begin{tabular}{|c|c|c|c|c|}
\hline \multirow{2}{*}{ Age (years) } & \multicolumn{2}{|c|}{ Gender } & \multirow{2}{*}{$\begin{array}{c}\text { Total } \\
\mathrm{N}\end{array}$} & \multirow{2}{*}{$\%$} \\
\hline & $\mathrm{F}$ & M & & \\
\hline 20 & 11 & 8 & 19 & 23.2 \\
\hline 21 & 14 & 11 & 25 & 30.5 \\
\hline 22 & 10 & 7 & 17 & 20.7 \\
\hline 23 & 1 & 7 & 8 & 9.8 \\
\hline 24 & 3 & 2 & 5 & 6.1 \\
\hline $25+$ & 1 & 7 & 8 & 9.8 \\
\hline Total (N) & 40 & 42 & 82 & 100.0 \\
\hline$\%$ & 48.8 & 51.2 & 100.0 & - \\
\hline Average age & 21.5 & 22.4 & 21.9 & - \\
\hline
\end{tabular}

F-Female; M-Male.

Table 2. Matching of visual perception and spectrophotometer Vita Easyshade.

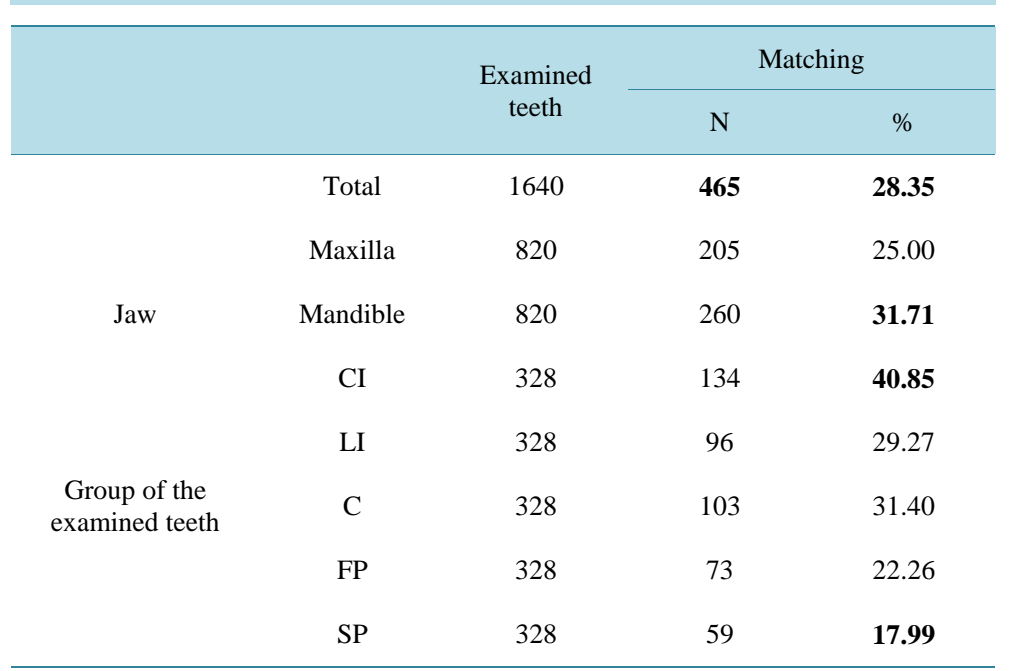

Central incisors, lateral incisors, canines, first premolars, second premolars.

$31.71 \%$, whereas in the upper jaw only $25 \%$. The central incisors showed the highest degree of agreement: $40.85 \%$, whereas second premolars only $17.99 \%$.

As the spectrophotometeric results are more reliable, differences in dental color perception between male and female observers with visual perception, is presented in Table 3. Female observers were successful $25.42 \%$. Male observers showed higher degree of matching between two methods: $30.65 \%$.

Teeth shades by visual perception are presented in Table 4 and Teeth shades by spectrophotometer readings are presented in Table 5. The most frequent supposed combination (MFSC) by visual perception was 2-M-2, whereas the most frequent shade (MFSh) for all examined teeth was 2M2-350 out of 1640 teeth-21.3\%. The most frequent supposed combination (MFSC) by Vita Easyshade was also 2-M-2, whereas the most frequent shade for all examined teeth was 2M3-256 out of 1640 teeth-15.6\%.

As the jaw is concerned, the combination of $\mathrm{L} / \mathrm{H} / \mathrm{C}$ for the upper jaw was: 2(36.3\%)-M(57.4\%)-2(27.8\%) and for the lower jaw 2(41.7\%)-M(72.1\%)-3(26.5\%). In the upper jaw there were 228 teeth with chroma level-2\% - 27.8\%, wheras in the lower jaw the chroma level—3 was found in 217 teeth-26.5\%. The most frequent shade 
Table 3. Differences in dental color perception between male and female observers.

\begin{tabular}{|c|c|c|c|c|c|c|c|c|}
\hline \multirow{2}{*}{ Tooth shade matching } & & \multicolumn{3}{|c|}{ Female observers } & \multicolumn{3}{|c|}{ Male observers } & \multirow{2}{*}{ Total } \\
\hline & & $\mathrm{F}$ & M & Total & $\mathrm{F}$ & M & Total & \\
\hline \multirow{2}{*}{ No } & $\mathrm{N}$ & 287 & 250 & 537 & 292 & 346 & 638 & 1175 \\
\hline & $\%$ & 75.53 & 73.53 & 74.58 & 69.52 & 69.20 & 69.35 & 71.65 \\
\hline \multirow{2}{*}{ Yes } & $\mathrm{N}$ & 93 & 90 & 183 & 128 & 154 & 282 & 465 \\
\hline & $\%$ & 24.47 & 26.47 & 25.42 & 30.48 & 30.80 & 30.65 & 28.35 \\
\hline Total & $\mathrm{N}$ & 380 & 340 & 720 & 420 & 500 & 920 & 1640 \\
\hline
\end{tabular}

F-Female subjects; M-Male subjects.

Table 4. Teeth shades by visual perception.

\begin{tabular}{|c|c|c|c|c|}
\hline \multirow{2}{*}{ Parameters } & \multirow{2}{*}{$\begin{array}{c}\text { Levels } \\
\text { (3D Master) }\end{array}$} & \multicolumn{2}{|c|}{ No. of teeth } & \multirow{2}{*}{$\begin{array}{l}\text { Average } \\
\text { intensity }\end{array}$} \\
\hline & & $\mathrm{N}$ & $\%$ & \\
\hline \multirow{8}{*}{$\mathrm{L}$} & 1 & 260 & 15.9 & 83.8 \\
\hline & 1.5 & 4 & 0.2 & 85.8 \\
\hline & 2 & 1200 & 73.2 & 82.9 \\
\hline & 2.5 & 8 & 0.5 & 80.9 \\
\hline & 3 & 154 & 9.4 & 81.1 \\
\hline & 4 & 12 & 0.7 & 81.4 \\
\hline & 5 & 2 & 0.1 & 83.9 \\
\hline & Grand total & 1640 & 100.0 & 82.9 \\
\hline \multirow{4}{*}{$\mathrm{H}$} & $\mathrm{L}$ & 333 & 20.3 & 91.6 \\
\hline & $\mathbf{M}$ & 1140 & 69.5 & 92.3 \\
\hline & $\mathrm{R}$ & 167 & 10.2 & 91.6 \\
\hline & Total & 1640 & 100.0 & 92.1 \\
\hline \multirow{7}{*}{$\mathrm{C}$} & 0.5 & 1 & 0.1 & 29.6 \\
\hline & 1 & 386 & 23.5 & 18.6 \\
\hline & 1.5 & 323 & 19.7 & 22.3 \\
\hline & 2 & 552 & 33.7 & 22.5 \\
\hline & 2.5 & 187 & 11.4 & 27.5 \\
\hline & 3 & 191 & 11.6 & 27.1 \\
\hline & Total & 1640 & 100.0 & 22.6 \\
\hline \multirow[t]{4}{*}{ MFSC of $\mathrm{L} / \mathrm{H} / \mathrm{C}$} & & & 2M2 & \\
\hline & Modality & 2 & M & 2 \\
\hline & $\%$ & 73.2 & 69.5 & 33.7 \\
\hline & Average & 82.9 & 92.3 & 22.5 \\
\hline \multirow[t]{3}{*}{ MFSh } & & Shade & \multicolumn{2}{|r|}{ 2M2 } \\
\hline & & $\mathrm{N}$ & \multicolumn{2}{|r|}{350} \\
\hline & & $\%$ & \multicolumn{2}{|r|}{21.3} \\
\hline
\end{tabular}

L-Lightness, H-Hue, C-Chrome; L, M, R (different groups of hue, MFSC: Most frequent supposed combination; MFSh: Most frequent shade). 
Table 5. Teeth shades by spectrophotometer Vita Easyshade.

\begin{tabular}{|c|c|c|c|c|}
\hline \multirow{2}{*}{ Parameters } & \multirow{2}{*}{$\frac{\text { Levels-Vita Easy }}{\text { Shade }}$} & \multicolumn{2}{|c|}{ No. of teeth } & \multirow{2}{*}{$\begin{array}{l}\text { Average } \\
\text { intensity }\end{array}$} \\
\hline & & $\mathrm{N}$ & $\%$ & \\
\hline \multirow{10}{*}{$\mathrm{L}$} & 0.5 & 1 & 0.1 & 88.6 \\
\hline & 1 & 79 & 4.8 & 88.4 \\
\hline & 1.5 & 297 & 18.1 & 86.1 \\
\hline & 2 & 640 & 39.0 & 83.6 \\
\hline & 2.5 & 453 & 27.6 & 80.8 \\
\hline & 3 & 137 & 8.4 & 77.9 \\
\hline & 3.5 & 29 & 1.8 & 74.6 \\
\hline & 4 & 3 & 0.2 & 74.9 \\
\hline & 4.5 & 1 & 0.1 & 68.9 \\
\hline & Total & 1640 & 100.0 & 82.9 \\
\hline \multirow{4}{*}{$\mathrm{H}$} & $\mathrm{L}$ & 536 & 32.7 & 92.4 \\
\hline & $\mathbf{M}$ & 1062 & 64.8 & 92.2 \\
\hline & $\mathrm{R}$ & 42 & 2.6 & 85.2 \\
\hline & Total & 1640 & 100.0 & 92.1 \\
\hline \multirow{6}{*}{$\mathrm{C}$} & 1 & 179 & 10.9 & 13.9 \\
\hline & 1.5 & 286 & 17.4 & 17.6 \\
\hline & 2 & 414 & 25.2 & 21.6 \\
\hline & 2.5 & 378 & 23.0 & 25.9 \\
\hline & 3 & 383 & 23.4 & 28.4 \\
\hline & Total & 1640 & 100.0 & 22.6 \\
\hline \multirow[t]{4}{*}{ MFSC of $\mathrm{L} / \mathrm{H} / \mathrm{C}$} & & & 2M2 & \\
\hline & Modality & 2 & M & 2 \\
\hline & $\%$ & 39.0 & 64.8 & 25.2 \\
\hline & Average & 83.6 & 92.2 & 21.6 \\
\hline \multirow[t]{3}{*}{ MFS } & & Shade & & 2M3 \\
\hline & & $\mathrm{N}$ & & 256 \\
\hline & & $\%$ & & 15.6 \\
\hline
\end{tabular}

L-Lightness, H-Hue, C-Chrome; L, M, R (different groups of hue, MFSC: Most frequent supposed combination; MFSh: Most frequent shade).

in both jaws was 2M3 (upper jaw-12.9\%, and lower jaw-18.3\%) Table 6.

In all 328 central incisors the lightness level was 1.5 - 118 teeth-36.0\%, hue level was M-253 teeth77.1\%, whereas chroma level-1.5-136 teeth-41.5\%. The most frequent supposed combination was $1.5 \mathrm{M} 1.5$. The most frequent shade was 1.5M1.5-61 teeth-18.6\%. In all 328 lateral incisors lightness level was $2-127$ teeth-38.7\%, hue level was $\mathrm{M}-183$ teeth-55.8\%; chroma level was $2-129$ teeth-39.8\%. The most frequent supposed combination was 2-M-2. The most frequent shade was $2 \mathrm{~L} 1.5-40$ teeth-12.2\%.

In all 328 canines, lightness level was 2.5-130 teeth-39.6\%, hue level was $\mathrm{M}-206$ teeth $-62.8 \%$ and chroma level 2.5-125 teeth-38.1\%. The most frequent supposed combination was 2.5-M-2.5. The most frequent 
Table 6. The most frequent supposed combination of color parameters by visual perception and Vita Easyshade.

\begin{tabular}{|c|c|c|c|c|c|c|c|c|}
\hline & & & \multicolumn{3}{|c|}{ Visual perception } & \multicolumn{3}{|c|}{ Vita Easyshade } \\
\hline & & & $\mathrm{L}$ & $\mathrm{H}$ & $\mathrm{C}$ & $\mathrm{L}$ & $\mathrm{H}$ & $\mathrm{C}$ \\
\hline \multirow[t]{3}{*}{ Total } & & & 2 & $\mathbf{M}$ & 2 & 2 & M & 2 \\
\hline & & $\%$ & 73.2 & 69.5 & 33.7 & 39.0 & 64.8 & 25.2 \\
\hline & Maxilla & & 2 & M & 2 & 2 & M & 2 \\
\hline \multirow[t]{7}{*}{ Jaw } & & $\%$ & 70.2 & 67.4 & 35.4 & 36.3 & 57.4 & 27.8 \\
\hline & Mandible & & 2 & $\mathbf{M}$ & 2 & 2 & $\mathbf{M}$ & 3 \\
\hline & & $\%$ & 76.1 & 71.6 & 32.0 & 41.7 & 72.1 & 26.5 \\
\hline & & & 2 & $\mathbf{M}$ & 1 & 1.5 & M & 1.5 \\
\hline & $\mathrm{Cl}$ & $\%$ & 62.5 & 79.0 & 49.4 & 36.0 & 77.1 & 41.5 \\
\hline & & & 2 & $\mathbf{M}$ & 2 & 2 & $\mathbf{M}$ & 2 \\
\hline & & $\%$ & 68.3 & 76.2 & 38.7 & 38.7 & 55.8 & 39.3 \\
\hline & & & 2 & M & 2.5 & 2.5 & $\mathbf{M}$ & 2.5 \\
\hline \multirow[t]{5}{*}{ Teeth group } & & $\%$ & 81.1 & 60.1 & 27.7 & 39.6 & 62.8 & 38.1 \\
\hline & & & 2 & $\mathbf{M}$ & 2 & 2 & $\mathbf{M}$ & 3 \\
\hline & & $\%$ & 79.3 & 66.2 & 38.7 & 49.1 & 65.5 & 37.5 \\
\hline & & & 2 & $\mathbf{M}$ & 2 & 2 & $\mathbf{M}$ & 3 \\
\hline & & $\%$ & 74.7 & 66.2 & 39.0 & 41.5 & 62.5 & 36.9 \\
\hline
\end{tabular}

L—Lightness; H—Hue; C—Chrome; CI—Central incisors; LI—Lateral incisors; C—Canines; FP—First premolars; SP—Second premolars.

shade was 2M3 - 66 teeth-20.1\%. In all 328 first premolars, lightness level was $2-161$ teeth $-49.1 \%$, hue level was $\mathrm{M}-215$ teeth $-65.5 \%$ and chroma level 3-123 teeth-37.5\%. The most frequent supposed combination was 2-M-3. The most frequent shade was $2 \mathrm{M} 3-94$ teeth-28.7\%.

In all 328 second premolars, lightness level was $2-136$ teeth-41.5\%, hue level was $M-205$ teeth $-62.5 \%$ and chroma level 3-121 teeth-36.9\%. The most frequent supposed combination was 2-M-3.

The most frequent shade was $2 \mathrm{M} 3-82$ teeth-25.0\%.

The most frequent supposed combination obtained by visual perception of all teeth was 2-M-2, whereas by Vita Easyshade, was also 2-M-2.

The most frequent supposed combination of color parameters by visual perception and Vita Easyshade.

The most frequent shade obtained by visual perception is $2 \mathrm{M} 2-350$ teeth-21.3\%, whereas with Vita Easyshade is 2 M3-256 teeth-15.6\%.

There is a slight difference of the shade between two methods, when the teeth of upper and lower jaw where matched. The most frequent real combination of the teeth in the upper jaw matched by visual perception is 2M2165 teeth-20.1\%, whereas with Vita Easyshade 2M3-106 teeth-12.9\%. Nearly the same was in the lower jaw.

According to the sides, the results were dominantly 2M2 for visual perception and 2M3 for Vita Easyshade.

The comparison of the results obtained by two methods on five groups of examined teeth showed the greatest accordance in canines 2M3 - 2M3; followed by central incisors 2M1 - 1.5M1.5; first premolars 2M2 - 2M3, second premolars 2M2 - 2M3 and finally the lateral incisors, which showed the greatest difference in accordance 2M1 - 2L1.5 (Table 7).

\section{Discussion}

In this study, the spectrophotometer Vita Easyshade was used to match natural teeth color and to compare it with 
Table 7. The most frequent shade of color parameters by visual perception and by Vita Easyshade.

\begin{tabular}{|c|c|c|c|c|c|c|c|}
\hline & & \multicolumn{3}{|c|}{ Visual perception } & \multicolumn{3}{|c|}{ Vita Easyshade } \\
\hline & & Shade & $\mathrm{N}$ & $\%$ & Shade & $\mathrm{N}$ & $\%$ \\
\hline Total & & 2M2 & 350 & 21.3 & $2 \mathrm{M3}$ & 256 & 15.6 \\
\hline \multirow[t]{4}{*}{ Jaw } & Maxilla & 2M2 & 165 & 20.1 & 2M3 & 106 & 12.9 \\
\hline & Mandible & 2M2 & 185 & 22.6 & 2M3 & 150 & 18.3 \\
\hline & CI & 2M1 & 96 & 29.3 & $1.5 \mathrm{M} 1.5$ & 61 & 18.6 \\
\hline & LI & 2M1 & 78 & 23.8 & $2 \mathrm{~L} 1.5$ & 40 & 12.2 \\
\hline \multirow[t]{3}{*}{ Teeth group } & $\mathrm{C}$ & $2 \mathrm{M3}$ & 94 & 28.7 & $2 \mathrm{M3}$ & 66 & 20.1 \\
\hline & FP & 2M2 & 89 & 27.1 & $2 \mathrm{M3}$ & 94 & 28.7 \\
\hline & SP & 2M2 & 84 & 25.6 & 2M3 & 82 & 25.0 \\
\hline
\end{tabular}

CI-Central incisors; LI-Lateral incisors; C-Canines; FP-First premolars; SP-Second premolars.

the colors of the same teeth determined by visual perception. When comparing the results of the two methods, there was a slight difference of shade between two jaws, two sides and teeth groups. Until the appearance of various color measuring devices for colour matching, only the visual perception as a method has been used. Visual perception has its disadvantages, based on individual capabilities of precise matching the parameters of colour.

Buckard Hugo et al. made a comparision between three actual devices for tooth color matching SpectroShade device (MHT Optic Research AG, 8155 Niederhasli, Switzerland), the ShadeVision device (X-Rite Co., Grandville, USA) and the Digital Shade Guide DSG4 (A. Rieth, 73614 Schorndorf, Germany) with a human observer's perception. They concluded that the agreement among the examiner group was $52.9 \%$, significantly better than that of each device compared to this group (31.3\% on average) and that color detection and its realization are very complex [19].

Individual differences in color perception can influence color matching results. The highest agreement between intrarater and intrarater shade matching consistency was for a single shade $39 \%$ and for the same shades $22 \%[20]$.

From our findings it can be interpreted that the accordance, between the results by Vita Easyshade and by visual perception were $28.25 \%$. The highest percentage of accordance was in central incisors $40.85 \%$, and the lowest in second premolars $17.99 \%$.

Paul et al. suggests that spectrophotometric shade analysis is more accurate and more reproducible compared with human shade assessment [21].

Klemetti et al. tested inter-observers variability in shade selection for porcelain restorations using three different shade guides: Vita Lumin Vacuum, Vita 3D Master and Procera and the digital colorimeter (Shade Eye Ex, Shofu, Japan). Between three shade guides there were no significant differences. Agreement with the colorimetric results was low $(8 \%-34 \%)$. They propose that the digital colorimeters may be a useful educational tool [22].

Sykora concluded that morphological and optical features of upper central incisiors are inadequate for color selection of all the teeth, especially of posteriors. Colors approximating first premolars are recomended for color selection in posterior teeth [23].

Goodkind and Schwabacher concluded that maxillary central incisors are the lightest and brightest teeth in the smile. The maxillary lateral incisors have a similar hue to that of the central incisors but are typically just slightly lower in color, or value. The canines have greater chroma saturation and also are lower in value than any of the other anterior teeth. First and second premolars appear lighter and brighter than the canines and have a value similar to that of the lateral incisors [24].

Our study showed that male observers had higher percentage of accordance between the two methods than females. Based on results, male observers, while matching teeth color were superior compared to females with a percentage of $30.65 \%$ for males with $25.42 \%$ for females. 
Q. Li and Y. N. Wang the shade matching difficulty degree analyzed through the agreements of visual shade selection. Within easy matching cases, the instrumental method achieved better results $(P=0.041)$. In conclusion, it was suggested that the reliability of shade matching can be ensured by neither the colorimeter nor the visual approach. However, they concluded that the colorimeter can achieve better results within easy matching cases [25].

James L. Donahue et al. found that during matching the teeth color by visual perception, the light source made a difference at female observers [26].

Judeh and Al-Wahadni concluded that Vita Easyshade spectrophotometer, needs further refinement, as well as software upgrades and that shade-matching devices could help clinicians and technicians achieve a better shade choice [27].

\section{Conclusions}

The accordance between the results of Vita Easyshade and visual perception was 28.25\%. The highest percentage of accordance was in central incisors $40.85 \%$, and the lowest in second premolars was $17.99 \%$.

The most frequent 3D Mastershade which was found by two methods was 2M2.

Male observers were superior in teeth color matching compared to females with a percentage of $30.65 \%$, for males with $25.42 \%$ for females.

The combination of visual shade analysis and digital shade measurement together lies in the precise predictability of the miscibility of shades.

\section{References}

[1] Paravina, R.D. and Powers, J.M. (2004) Esthetic Color Training in Dentistry. St Louis, Mosby.

[2] Vaarkamp, J., ten Bosch, J.J. and Verdonschot, E.H. (1995) Propagation of Light through Human Dental Enamel and Dentine. Caries Research, 29, 8-13. http://dx.doi.org/10.1159/000262033

[3] ten Bosch, J.J. and Coops, J.C. (1995) Tooth Color Reflectance as Related to Light Scattering and Enamel Hardness. Journal of Dental Research, 74, 374-380. http://dx.doi.org/10.1177/00220345950740011401

[4] Tripodakis, A.P. (1989) Shade Selection in Fixed Prosthodontics. Odontostomatol Proodos, 43, 539.

[5] Bergen, S.F. (1985) Color in Esthetics. The New York State Dental Journal, 51, 470.

[6] Yorty, J.S., et al. (2000) A Simple Screening Test for Color Matching in Dentistry. General Dentistry, 48, 272.

[7] Donahue, J.L., et al. (1991) Shade Color Determination by Men and Women. The Journal of Prosthetic Dentistry, 65, 699-703. http://dx.doi.org/10.1016/0022-3913(91)90209-F

[8] Paravina, R.D. (1999) Instrumental Color Matching Methods in Dentistry. Andrejević Foundation, Belgrade.

[9] Davison, S.P. and Myslinski, N.R. (1990) Shade Selection by Color Vision-Defective Dental Personnel. The Journal of Prosthetic Dentistry, 63, 97-101. http://dx.doi.org/10.1016/0022-3913(90)90276-I

[10] McMaugh, D.R. (1977) A Comparative Ability of the Colour Matching Ability of Dentists, Dental Students and Ceramic Technicians. Australian Dental Journal, 22, 165-167. http://dx.doi.org/10.1111/j.1834-7819.1977.tb04482.x

[11] Wasson, W. and Schumann, N. (1992) Color Vision and Dentistry. Quintessence International, 23, 349-353.

[12] Moser, J.B., Wozniak, W.T., Naleway, C.A. and Ayer, W.A. (1985) Color Vision in Dentistry: A Survey. Journal of the American Dental Association, 110, 509-510.

[13] Barna, G.J., Taylor, J.W., King, G.E. and Pelleu, G.B. (1981) The Influence of Selected Light Intensities on Color Perception within the Color Range of Natural Teeth. Journal of Prosthetic Dentistry, 46, 450-453. http://dx.doi.org/10.1016/0022-3913(81)90456-X

[14] Okubo, S.R., Kanawati, A., Richards, M.W. and Childress, S. (1987) Evaluation of Visual and Instrument Shade Matching. Journal of Prosthetic Dentistry, 80, 642-648.

[15] Roge, M. and Preston, J.D. (1987) Color, Light and the Perception of Form. Quintessence International, 18, $391-396$.

[16] Pascual-Moscardó, A. and Camps-Alemany, I. (2006) Aesthetic Dentistry: Chromatic Appreciation in the Clinic and the Laboratory. Medicina Oral, Patología Oral y Cirugía Bucal, 11, E363-E368.

[17] Fani, G. and Vichi, A. (2007) Spectrophotometric and Visual Shade Selection Based of Two Shade Guide. American Journal of Dentistry, 20, 142-146.

[18] Ahmad, I. (2006) Protocols for Predictable Aesthetic Dental Restorations, 4th Chapter, Colour and Shade Analysis. Blackwell Munksgaard, Oxford, 77-97. 
[19] Hugo, B., Witzel, T. and Klaiber, B. (2005) Comparison of in Vivo Visual and Computer-Aided Tooth Shade Determination. Clinical Oral Investigations, 9, 244-250.

[20] Culpepper, W.D. (1970) A Comparative Study of Shade-Matching Procedures. Journal of Prosthetic Dentistry, 24, 166-173. http://dx.doi.org/10.1016/0022-3913(70)90140-X

[21] Paul, S., Peter, A., Pietrobon, N. and Hämmerle, C.H.F. (2002) Visual and Spectrophotometric Shade Analysis of Human Teeth. Journal of Dental Research, 81, 578-582.

[22] Klemetti, E., Matela, A.M., Haag, P. and Kononen, M. (2006) Shade Selection Performed by Novice Dental Professionals and Colorimeter. Journal of Oral Rehabilitation, 33, 31-35. http://dx.doi.org/10.1111/j.1365-2842.2006.01531.x

[23] Sykora, O. (1983) Fabrication of a Posterior Shade Guide for Removable Partial Dentures. Journal of Prosthetic Dentistry, 50, 287-288. http://dx.doi.org/10.1016/0022-3913(83)90033-1

[24] Goodkind, R.J. and Schwabacher, W.B. (1987) Use of a Fiber-Optic Colorimeter for in Vivo Measurements of 2,830 Anterior Teeth. Journal of Prosthetic Dentistry, 58, 535-542. http://dx.doi.org/10.1016/0022-3913(87)90380-5

[25] Li, Q. and Wang, Y.N. (2007) Comparison of Shade Matching by Visual Observation and an Intraoral Dental Colorimeter. Journal of Oral Rehabilitation, 34, 848-854. http://dx.doi.org/10.1111/j.1365-2842.2006.01678.x

[26] Donahue, J.L., Goodkind, R.J., Schwabacher, W.B. and Aeppli, D.P. (1991) Shade Color Determination by Men and Women. Journal of Prosthetic Dentistry, 65, 699-703. http://dx.doi.org/10.1016/0022-3913(91)90209-F

[27] Judeh, A. and Al-Wahadni, A. (2009) A Comparison between Conventional Visual and Spectrophotometric Methods for Shade Selection. Ajman University of Science \& Technology, Ajman.

\section{Abbreviations}

F-Female

M-Male

L-Lightness

$\mathrm{H}-$ Hue

C-Chrome

MFSC-Most frequent supposed combination

MFSh-Most frequent shade

CI-Central incisors

LI-Lateral incisors

C-Canines

FP-First premolars

SP-Second premolars 
Scientific Research Publishing (SCIRP) is one of the largest Open Access journal publishers. It is currently publishing more than 200 open access, online, peer-reviewed journals covering a wide range of academic disciplines. SCIRP serves the worldwide academic communities and contributes to the progress and application of science with its publication.

Other selected journals from SCIRP are listed as below. Submit your manuscript to us via either submit@scirp.org or Online Submission Portal.
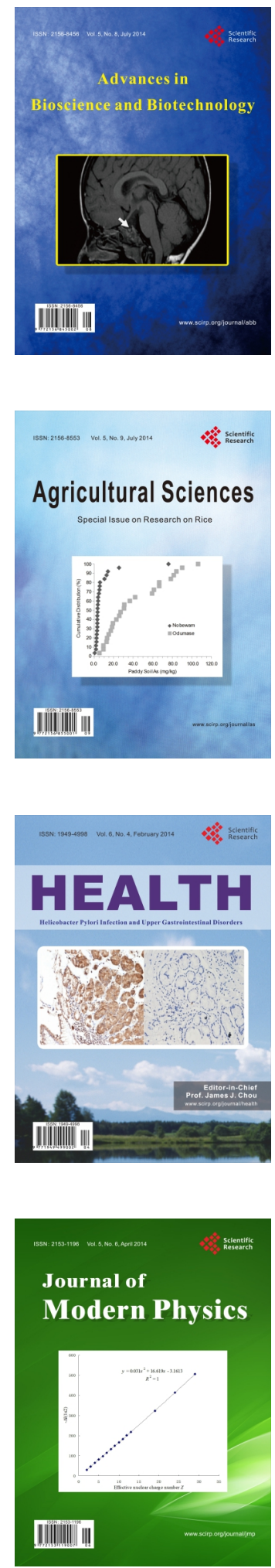
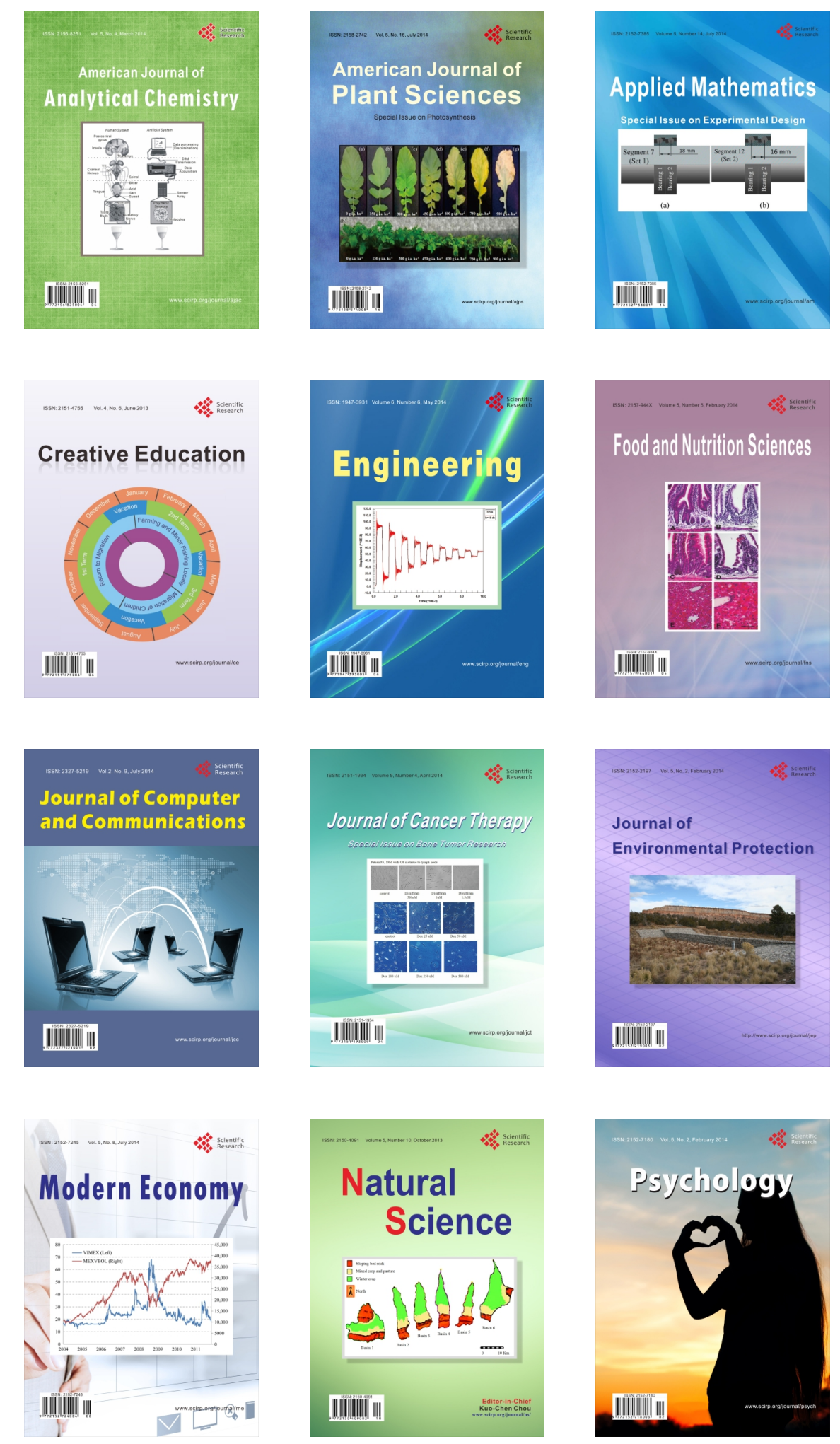